\title{
THE EVOLUTION OF MANAGEMENT: A HISTORICAL PERSPECTIVE https://doi.org/10.47743/jopafl-2021-22-15
}

\author{
Ugo Chuks OKOLIE \\ Department of Political Science, Delta State University, \\ Abraka, Nigeria \\ ugookolie3@gmail.com \\ Uzezi Eniyome OYISE \\ Delta State Polytechnic, Ogwashi - Uku, \\ Nigeria \\ uziblack2000@yahoo.com
}

\begin{abstract}
Management is a challenge requiring constant adaptation to new circumstances because globalization, technological change, the importance of knowledge and collaboration across organizational boundaries have make the current business landscape different from the past decades, it is pertinent to have an understanding of the origins of management thought. It is against this backdrop that this paper examines the evolution of management thought through the decades. This paper adopted quantitative research method through textual analysis and concludes that companies, like individuals, fail or succeed for a variety of reasons. Some of these reasons are circumstantial. Most are personal and human and include the decisions managers make and the actions they take.
\end{abstract}

Keywords: Management, Manager, Evolution of Management, Efficiency, Effectiveness

\section{Introduction}

For thousands of years, managers have wrestled with the same issues and problems confronting executives today. Around 1100B.C, the Chinese practiced the four management functions planning, organizing, leading, and controlling. Between 400B.C and 350B.C, the Greeks recognized management as a separate art and advocate a scientific approach to work. The Romans decentralized the management of their vast empire before the birth of Christ. During medieval times, the venations standardized production through the use of an assembly line, building warehouses and using an inventory system to monitor the content. But throughout history, most managers operated strictly on a trial-and-error basis. The challenges of the industrial revolution changed that. Management emerged as a formal discipline at the turn of the century. The first University programs to offer management and business education, the Wharton school at the University of Pennsylvanian and the Amos Tuck school of Dartmouth, where founded in the late 19th century. By 1914, 25 business schools existed. Thus, the management profession as we know it today is relatively new. Understanding the origins of management though will help you grasp the underlying contexts of the ideas and concepts management as a challenge requiring constant adaptation to new circumstances. The Evolution of Management may be more appropriately called "The Revolution of Management”, because it documents the wide swings in management approaches over the last 100 years. Out of the great variety of 
ideas about how to improve management, parts of each approached have survived and been incorporated into modern perspectives on management. Thus, the legacy of past efforts, triumphs, and failures has become our guide to present and future management practice.

\section{Early Management Concepts and Influences}

Communications and transportation constraints hindered the growth of earlier business. Therefore, improvement in management techniques did not substantially improve performance. However, the industrial evolution changed that. As companies gr3ew and became more complex, minor improvements in management tactics produced impressive increases in production quantities and quality. The emergence of economics of scalereductions in the average cost of a unit of production as the total volume produced increases-drove management to strive for further growth. The opportunities for mass production created by the industrial revolution spawned intense and systematic through about management problems and was particularly efficiency, production processes and cost savings. This paper provides a timeline depicting the evolution of management thought through the decades. This historical perspective is divided into two major sections. Classical and contemporary approaches; many of these approaches overlapped as they are developed and they often had a significant impact on one another. Some approaches were a direct reaction to the perceived deficiencies of previous approaches. Others developed as the needs and issues confronting managers changed over the years. All the approaches attempted to explain the real issues facing managers and provide them with tools to solve future problems. This paper will reinforce your understanding of the key relationships among the approaches and place each perspective in its historical context.

\section{Classical Approaches}

The classical period extended from the mid-19th century through the early 1950s. The major approaches that emerged during the period were systematic management, human relations and bureaucracy.

Systematic Management: During the 19th century, growth in U.S. businesses centered on manufacturing. Early writers such as Adam Smith believed the management of these firms was chaotic and their ideas helped to systematize it. Most organizational tasks were subdivided and performed by specialized labour. However, poor coordination caused frequent problems and breakdowns of the manufacturing processes. The systematic management approach attempted to build specific procedures and processes into operations to ensure coordination of systematic management emphasized economical operations, adequate staffing, maintenance of inventions to meet consumer demand, and organizational control. These goals were achieved through:

1. Control definition of duties and responsibilities.

2. Standardized techniques for performing these duties.

3. Specific means of gathering, handing, transmitting and analyzing information.

4. Cost accounting, wage, and production control systems to facilitate internal coordination communications.

Systematic management emphasized internal operation because managers were concerned primarily with meeting the explosive growth in demand brought about the 
industrial revolution. In addition, managers were free to focus on internal issues of efficiency. In fact, this is because the government did not constrain business practices significantly. Finally, labour was poorly organized. As a result, many managers were oriented more toward things than forward people.

Systematic management did not address all the issues 19th century managers faced, but it tried to raise managers' awareness about the most pressing concern of their job. Scientific management failed to lead to wide spread production efficiency. This is short coming became apparent to a young engineer name Frederick Taylor, who was hired by Miduale Steel Company in 1818. Taylor discovered that production and pay were poor, inefficiency and waste were prevalent and most companies have recommended unused potential. He concluded that management decisions were unsystematic and that no research to determine the best means of production existed. In response, Taylor introduced approach to management known as scientific management. This approach advocated the application of scientific methods to analyze work and to determine how to complete production tasks efficiently. For examples U.S. Steels' contract with the United Steel worker of America specified that sand shovels on average is pounds of river sand composed of 5.5 percent moisture. Taylor identified four principles of scientific management:

1. Management should develop a precise, scientific approach for each element of one's work to replace general guidelines.

2. Management should scientifically select, train, teach and develop each worker so that the right person has the right job.

3. Management should cooperate with workers to ensure that jobs match plans and principles.

4. Management should ensure an appropriate division of work and responsibility between managers and workers.

To implement this approach, Taylor used techniques such as time-and-motion studies. With this technique, a task was divided into its basic movement and different motions were timed to determine the most effective way to complete the task, after the "one best way" to perform the job was identified. Taylor stressed the importance of hiring and training the proper worker to do that job. Taylor advocated standardization of tools, the use of instruction cards to help worker and brakes to eliminate fatigue. Another key element in Taylor's approach was that of the differential piece rate system. Taylor assumed workers were motivated by receiving money. Therefore, he implemented a pay system in which workers were paid additional wages when they exceed a standard level of output for each job. Taylor concluded that both workers and management would benefit from such an approach.

Scientific management principles were widely embraced. Other proponent, including Henry Fran and Lilian Gilbreth, introduced many refinements and technique for applying scientific management on the factory floor. One of the most famous examples of the application of scientific management is the Factory; Henry Ford built to produce the model T. The legacy of Taylor's scientific management approach is broad and pervasive; most important, productivity and efficiency in manufacturing improve dramatically. The concept of scientific method and research were introduced to manufacturing, the scientific management gained wide acceptance because of its more closely aligned effort and reward. Taylor also emphasized the need for cooperation between management and workers. And the concept of a management specialist gained prominence. 
Despite these gains, not everyone was convinced that scientific management was the best solution to all business problems. First, critics claimed that Taylor ignored many job-related social and psychological factors by emphasizing only money as a worker incentive. Second, production tasks were related to a set of routine machines producers that led to boredom, apathy and quality control problems. Third, unions strongly opposed scientific management techniques because they believed management might abuse their power to set the standard and thus exploiting workers and diminishing their importance. Finally, although scientific management resulted in intense scrutiny of internal efficiency of organization, but it did not help managers deal with broader external issues such as competitors and government regulations, especially at the senior management level.

Administrative Management: The administrative management approach emphasized the perspective of senior management within the organization and argued that management was a profession and could be taught. An explicit and broad framework for administrative management emerged in 19156, when Henri Fayol, a French mining engineer and executive. Fayol identified five functions and 14 principles of management. The five functions, which were very similar to the four functions mention above, are planning, commanding, coordinating and controlling. A host of other executives contributed to the administrative management literature. These writers discussed a broad specimen of management topics, including the social responsibilities of management, the philosophy of management, clarification of business terms and concept and organizational principles. Chester Bernard's and Mary Parker Follet's contribution have become classic works in this area. Bernard former president of New Jersey Bell Telephone Company published his mark book "The function of the executive" in 1938. He outlined the role of the senior executive to include emulating the purpose of the organization, hiring key individuals and maintaining organizational communications. Mary Parker Fallet’s 1942 book "Dynamic Organization" extended Bernard's work by emphasizing the continually changing situation that managers face. Two of her key contributions are (1) the notion that mangers desire flexibility and the differences between motivating groups and individuals and (2) laid the ground work for the modern contingency approach.

All the writings in the administrative management area emphasize management as a profession along with fields, such as law and medicines. In addition, these authors offered many recommendations based on their personal experiences, which often included managing large corporations. Although, these perspectives and recommendations were considered sound, critics noted that they might not work in all settings. Different types of personnel, industry conditions and technologies may affect the appropriateness of these principles. Fayol 14 principles of management:

1. Division of work: Divide work into specialized task and assign responsibilities to specific individuals.

2. Authority: Delegate authority along with responsibility.

3. Discipline: Make expectations clear and punish violation.

4. Unity of command: Each employee should be assigned to only one supervisor.

5. Unity of direction: Employees' effort should be focused on achieving organizational objectives.

6. Subordination of individual interest to the general interest: The general interest must predominate. 
7. Remuneration: Systematically reward effort that support the organization's direction

8. Centralization: Determine the relative importance of superior and subordinates' roles.

9. Scalar chain: Keep communication with the scale of command.

10. Order: Order jobs and materials so they support the organizations directives.

11. Equity: Fair discipline and order enhance employee commitment.

12. Stability and tenure of personnel: Promote employee loyalty and longevity.

13. Initiative: Encourage employees to act on their one in support of the organization's direction.

14. Espirit the corps: Promote a unity of interests between employees and management.

Human Relations: The human relations developed during the 1930s aimed at understanding how psychological and social processes interact with the work situation to influence performance. Human relations was the first major approach to emphasizing informal work relationships and workers' satisfaction. The approach owes much to other major school of thought for example, many of the ideas of the Gilberts (scientific management) and Bernard and Follet (administrative management) influenced the development of human relations from 1930 to 1955. In fact, human relation emerged from a research project that began as a scientific management study. Western Electric Company, a manufacturer of communication equipment, hired a team of Harvard researchers led by Elton Mayo and Fatz Roethlisberger. They were to investigate the influence of physical working conditions on work productivity and efficiency in one of the company's factory outside Chicago. This research project known as the Hawthorne studies provides some of the most interesting and controversial result in the history of management.

The Hawthorn studies were a series of experiment conducted from 1924 to 1932. During the first stage of the project, various working conditions to particularly the lighting in the factory were altered to determine the effects of their changes on productivity. The researchers found no systematic relationship between the factory lighting and production levels. In some cases, productivity continued to increase even when the illumination was reduced to the level of moonlight. The researchers conclude that the workers performed and reacted differently because the researchers were absenting them. This reaction is known as Hawthorn effect. This conclusion led the researchers to believe that productivity may be affected more by psychological and social factors than by physical or objective influences. With this taught in mind, they initiated the other four stages of the project. During this stage the researchers perform various work group experiment and had extensive interview with employees. Mayo and his team eventually concluded that productivity and employee behaviour were influenced by the informal work group. Another noted contributor to human relations was Abraham Maslow in 1934; Maslow suggested that humans have five levels of need. The most basic needs are the physical need for food, water and shelter. The most advanced need is for self-actualization or personal fulfilment. Maslow argued that people try to satisfy their lower levels needs and then progress upward to the higher-level needs. Managers can facilitate this process and achieve organizational goals by removing obstacles and encouraging behaviour that satisfy people needs and organizational goals simultaneously. 
Human relations proponent argued that mangers should stress primarily employee welfare, motivation and communication. They believed social needs and precedence are economic needs. Therefore, management must put into account the corporation of the group and promotes job satisfaction and group norms consistent with the goals of the organization. Although, the human relations approach generated research into leadership, job attitudes and group dynamics, it drew heavy criticism. Critics believed that one result of human relations - a belief that a happy worker was a productive worker was too simplistic. While scientific management overemphasized the economic and formal aspect of the workplace, human relations ignored the more rational sides of the workers and the important characteristics of the formal organization. However, human relations is a significant step in the development of management thought, because it promoted mangers and researchers to consider the psychological and social factors that influence performance.

Bureaucracy: Max Weber, a German Sociologist, lawyer and social historian, showed how management itself could be more efficient and consistent in his book "the theory of social and economic organizations". The ideal model for management according to Weber is the bureaucracy approach. Weber believed bureaucratic structures can eliminate the variability that result when managers in the same organization have different skills, experiences and goals. Weber advocated that the jobs themselves be standardized so that personnel changes would not disrupt the organization. He emphasized a structure; formal network of relationships among specialized positions in an organization. Rule and regulation standardize behaviour and authority resides in position rather than individual as a result, the organization need not rely on a particular individual, but will realize efficiency and success by following the rule in a routine and unbiased manner. According to Weber, bureaucracies are especially important because they allow large organization to perform the many routine activities necessary for their survival. Also, bureaucratic position foster specialized skills, eliminating many subjective judgements by managers. In addition, if the rules and controls are established properly, both customers and employers.

Many organizations today are bureaucratic; Bureaucracy is efficient and productive, however bureaucracy is not the appropriate model for every organization, organizations or department that need rapid decision making and flexibility may suffer under bureaucratic approach. Some people may not perform their best with excessive bureaucratic rules and procedures.Other short comings stem from faulty executives of bureaucratic principles rather than from the approach itself, too much authority may be vested in too few people. The procedure may become the ends than the means. Finally, one advantage of a bureaucracy is performance; it can also be a problem. Once a bureaucratic is established, dismantling it is very difficult.

\section{Contemporary Approaches}

The contemporary approaches to management include quantitative management, organizational behaviour, system theory and the contingency perspective. The contemporary approaches have developed at various times since World War II, and they continue to represent the cornerstone of modern management thought.

Quantitative Management: Although Taylor introduced the use of science as a management tool early in the 20th century. Most organizations did not adopt the use of 
quantitative techniques for management problems until the 1940s and 1950s during World War II, military planners began to apply mathematical techniques to defuse logistics problems after the War private corporations began assembling teams of quantitative experts to tackle many of the complex issues confronting large organizations. This approach referred to as quantitative management which emphasizes the application of quantitative analysis to management decisions and problems. Quantitative management helps a manager make a decision by developing formal mathematical models of the problem computers facilitated the development of specific quantitative methods. These include such techniques as statistical decision theory linear programming, queuing theory, simulation, forecasting, inventory, modeling, network modelling and break even analysis, organization apply these techniques in many areas including production quality control, marketing human resources finance, distribution, planning and research and developing. Despite the promise quantitative management holds, managers do not rely on these method as the primary approach to decision making. Typically, they use this technique as a supplement or tool in the decision process. Many managers will use results that are consistent with their experience, institution and judgement, but they often reject results that contradict their beliefs. Also, managers may use the process to compare alternatives and eliminate weaker options. Several explanation accounts for why many manager have not been trained in using these techniques, also many aspects of a management decision cannot be expressed through mathematical symbols and formulas. Finally, many of the decision managers' face are non-routine and unpredictable.

Organizational behavior: During 1950's, a transition took place in the human relations approach, scholars began to recognize that workers' productivity and organization success are based on more than the satisfaction of economic or social needs. The revised perspective known as organizational behaviour studies and identifies management activities that promote employee effectiveness through an understanding of the complex nature of individual, group and organizational processes. Organizational behaviour draws from a variety of disciplines including psychology and sociology to ensure the behaviour of people on the job. During the 1960's, organizational behaviorists heavily influenced the field of management. Douglas McGregor's Theory X and Y marked the transition from human relations according to McGregor's Theory X, managers assume workers are lazy and irresponsible and require constant supervision and external motivation to achieve organizational goals. Theory Y managers assume employees want to work and can direct and control themselves McGregor advocated a theory $\mathrm{Y}$ perspective, suggesting that managers who encourage participation and allows opportunities for individual challenge and initiative would achieve superior performance. Other major organizational behavourists include Chris Argyris, who recommended greater autonomy and better jobs for workers and Rensis Likert, who stressed the value of participative management. Through the years, organizational behaviours has consistently emphasized development of the organization's human resources to achieve individual and organizational goals like other approaches, it has been categorized for its limited perspective, although more recent contributions have a broader and more situational viewpoint. In the past few years, many of the primary issues addressed by the organizational behaviour have experienced a rebirth with a greater interest in leadership, employee involvement and self-management.

The classical approaches as a whole were criticized because they (1) ignored the relationship between the organization and its external environment and (2) usually stressed 
one aspect of the organization or its employees at the expense of other consideration. In response to this criticism, management scholars during the 1950s stepped back from the details of the organization to attempt to understand it as a whole system. These effort were based on a general scientific approach called system theory organizations are open system, dependent on input from outside world,such as raw materials, human resources and capital. They transform these inputs into outputs that (ideally) meet the market's needs for goods and service. The environment reacts to the outputs through a feedback loop. This feedback provides inputs for the next cycle of the system. The process repeats itself for the life of the system. System theory also emphasizes that an organization is one system in a series of subsystems. For instance, southwest Airlines is a subsystem of the airline industry and the flight crews are a subsystem of southwest. Systems theory points out that each subsystem is a component of the whole and is interdependent with other subsystem.

Contingency perspective: Building on system theory ideas, the contingency perspective refutes universal principles of management by stating that a variety of factors, both internal and external to the firm, may affect the organization's performance. Therefore, there is no "one best way" to manage and organize, because circumstance varies. Situational characteristics are called contingencies, understanding contingencies helps a manager know which set of circumstances dictate which management actions. The contingencies include:

1. Circumstances in the organization's external environment.

2. The internal strengths and weaknesses of the organization.

3. The values, goals, skills and attitude of managers and workers in the organization.

4. The type of task resources and technologies the organization uses.

In understanding contingencies, managers may categories the situation and then choose the proper competitive strategy, organization struggle or management process for the circumstances. Researchers continue to identify key contingency variable and their effect on management issues. As your read the topic covered each chapter, you will notice similarities, and differences among management situations and the appropriate responses. The perspective should represent a cornerstone of your own approach to management.

\section{An Eye on the Future}

All of these historical perspectives have left legacies that affect contemporary management thought and practice. Their understanding continues to flow, even as the context and the specifics change. Times do pass, and the things do change. This may sound obvious, but it is not firms fail to adapt to changing times. Business becomes global. New technologies have change how we work, produce goods and delivers services; change continually creates both new opportunities and new demands for lowering cost and for achieving greater innovation, quality and speed. Management knowledge and practices evolve accordingly. The essential facts about change are these: First, change is happening more rapidly and dramatically than at any other time in history. Second, if you don't anticipate change and adapt to it, you and your firm will not thrive in a competitive, business world. The theme of change - what is happening now, what lies ahead, how it affects management and how you can deal with it. What are the implications of these changes for you and your cares, how can you best be readily to meet the challenge? You 
must ask questions about the future, anticipate changes, know your responsibilities and be prepare to meet them head on.

\section{Conclusion}

This paper provides a historical perspective of management thought as the needs and issues confronting mangers changed over the years. Some of the approaches about how to improve management survived and been incorporated into modern perspectives of management. The legacies of past efforts, triumphs and failures have become our guide today and to future management practice. In conclusion therefore, there is not replacement for effective management. Companies like individuals, fail or succeed for a variety of reasons. Some of these reasons are circumstantial. Most are personal and human and include the decisions mangers make and the actions they take.

\section{References}

1. Bateman, T. S. \& Snell, S. A. (2011). Management: Leading \& collaborating in a competitive world (9th edition). United States; McGraw-Hill.

2. Halligan, J. (2007). Leadership and the senior service from a comparative perspective. In B.G. Peter \& J. Pierre (eds). The handbook of public administration. London; Sage Publications, pp. 63-73.

3. Krietner, R., \& Kinicki, A. (1994). Organization behaviour (3rd edition). New York: Richard D. Irwin.

4. Mukoro, A. ( 2019). Public administration: Practice and theory in Nigeria. Ibadan: Ababa Press Ltd.

5. Mukoro, A. ( 2020). Administration of the public service. Ibadan: Ababa Press Ltd.

6. Ricketts, K. G. (2005). The importance of community leadership to successful rural communities in Florida. A Ph.D Thesis Florida; Post Graduate school of the University of Florida. Pp 1-234.

7. Sullivian, V. (1954). The principles OF scientific management. New York: Harper \& Row.

8. Welsh, T. (1994). Best and worst corporate reputations: Fortune, February 7, 58-66. 